\title{
Knowledge Level about HIV/AIDS among the Villagers of Comilla District, Bangladesh
}

\author{
Md. Shafiur Rahman1, Md. Nuruzzaman Khan2*, Md. Nazrul Islam Mondal2, \\ Md. Shamsher Alam³, Kazi Mohiuddin Ahmed", Md. Rafiqul Islam² \\ ${ }^{1}$ Department of Public Health, First Capital University of Bangladesh, Chuadanga, Bangladesh \\ ${ }^{2}$ Department of Population Science and Human Resource Development, University of Rajshahi, Rajshahi, \\ Bangladesh \\ ${ }^{3}$ Faculty of Ecology, Peoples' Friendship University of Russia, Moscow, Russia \\ ${ }^{4}$ Department of Community Medicine, Pabna Medical College, Pabna, Bangladesh \\ Email: sumonrupop@gmail.com
}

Received 20 September 2014; revised 18 October 2014; accepted 15 November 2014

Copyright (C) 2014 by authors and Scientific Research Publishing Inc.

This work is licensed under the Creative Commons Attribution International License (CC BY).

http://creativecommons.org/licenses/by/4.0/

(c) (i) Open Access

\section{Abstract}

The HIV/AIDS epidemic has grown on an unprecedented scale since it was first recognized, and presently it is considered as a well known global public health crisis. In making the health policy where millions of populations are at risk, it is necessary to understand the knowledge level about HIV/AIDS. So, this study aimed at to investigate the knowledge level about HIV/AIDS among the villagers. Data and necessary information were collected from one hundred villagers of Salmanpur from Comilla district, Bangladesh through a structured questionnaire. The collected data were used for univariate analysis, to carry out the description of the variables; and to justify the total score of knowledge about HIV/AIDS among the respondents, Cronbach's alpha $(\alpha)$ was calculated. The results revealed that almost all the respondents $(\mathbf{9 2 . 0 0 \% )}$ were ever heard about HIV/AIDS and half of them $(51.00 \%)$ were known it as a communicable disease. Majority of the respondents $(62.00 \%)$ believed that it is caused by heterosexual relation as well as sex with HIV positive persons. However, a good number of respondents were found unaware about the major causes and preventive ways of AIDS. Less than half of the respondents $(45.00 \%)$ had medium knowledge ( $\alpha=$ $0.34-0.66$ ) and only $36.00 \%$ had the enough knowledge about HIV/AIDS. The knowledge level is increasing with the increase of education level, and the respondents who involved in agricultural works are found the lowest knowledge level (47.00\%) about HIV/AIDS. The villagers were known about HIV/AIDS but they do not have accurate information about the ways in which AIDS virus can or cannot be transmitted. Therefore, effective programs should be taken to increase the knowledge level about HIV/AIDS among the villagers in Bangladesh.

\footnotetext{
*Corresponding author.
} 


\section{Keywords}

\section{AIDS, Villagers, Sexually Transmitted Diseases, Cronbach's Alpha, Bangladesh}

\section{Introduction}

Human Immunodeficiency Virus (HIV) is one kind of virus and Acquired Immune Deficiency Syndrome (AIDS) is a killer diseases caused by HIV. It is continuous to be very common and complicated man killer diseases globally since it was first recognized in 1981 [1]. Once HIV starts damaging the immune system of human body, it ultimately transformed to AIDS and finally death [2]. The virus is generally transmitted through sexual contact, from infected women to their unborn children or through contaminated needles or blood [3]. Among the risk factors, sexual behavior is considered as the most significant predictor [4]-[6]. The disease AIDS has speared all over the world and the millions of people have been victimized by its prolong and sharp claw which leading to the largest causes of death in the world and placed fourth [7]-[9]. In 2012, almost 2.30 million people were HIV infected which was 3.50 million in 1990 [8]. Though the number of HIV infected people continues to fall but the actual number is quite significant. Around 35.50 million (Adults 32.10 million, women 17.70 million, children 3.30 million) people are currently living with HIV [8]. The total number of deaths due to AIDS is also quite significant. In 2012, total of 1.60 million deaths recorded due to AIDS [8]. The number of deaths is probably peaked in 2005 (2.30 million), and has declined only slightly. Globally, around $11.00 \%$ HIV infections were the babies who acquired this virus from their mothers and 17.80 million children were lost one or both parents to AIDS [10]. Furthermore, $10.00 \%$ were infected through the injecting drug use; $5.00 \%-10.00 \%$ was due to the sex between men; and 5.00\% - 10.00\% occurred in health care setting [8]. The Sub-Saharan Africa is considered as the most affected area of HIV in the world [10]. Though this rate showed the decreasing trend in the present time and almost $40.00 \%$ drop between the years 2001 (2.6 million) to 2012 (1.6 million) but about one million fewer people acquired HIV in 2012 in the Sub-Saharan area [8]. In the Middle East and the North Africa, the number of HIV infected people rose by more than 50.00\% and increased from 21,000 in 2001 to 32,000 in 2012 [11]. Again, in Caribbean nation about 50.00\% HIV infection fell and 12,000 HIV infected patients in 2012 which was declined from 25,000 in 2001 [8]. In the South and the South-East Asia there were one-third decreased in the number of people living with HIV from 2001 to 2012 [11].

Importantly the HIV epidemic in Asia is increased in the recent periods [11]. In the early to mid-1980's, while others parts of the world were first beginning to deal with serious AIDS epidemic, Asia remained relatively unaffected by this newly discovered health problem. By the early 1990s, however, epidemic had emerged in several Asian countries and by the end of that decade; HIV is spreading rapidly in many areas of this continent [12]. In 2012, there were 81,000 HIV infected people in this continent which is rose from 68,000 in 2001 [13]. As in the Asian countries with its more than 150 million populations, Bangladesh is still fortunate to be a low prevalent country $(<0.001 \%)$ for HIV/AIDS [14]. The first case of HIV in Bangladesh was detected in 1989. Until December 2012, there were 8000 reported cases of HIV and 1299 cases of AIDS, of which 472 deaths were officially recorded [14]. Bangladesh continues to be a low the prevalence country, but at present with high prevalence of risk behaviors and the effects of the western and Indian cultures, the country has lost its moral and traditional values which put it in more vulnerable situation. Moreover, higher prevalence of HIV/AIDS in the neighboring countries i.e. India and Myanmar put the country at high risk [15]. Again almost all of the risk factors that facilitate rapid transmission of HIV infection, such as a large number of hidden sex industry, lower levels of condom use, increasing injecting drug use and persistent sharing practices are presented here [14] [16] [17]. There were only forty establish prostitutions in Bangladesh but all the residential hotels (ranging from higher to low class) in the major cities are thriving on sex business and important studies of the sex industry identified about 1,70,000 professional sex workers whose customers are in all segments of the society [16]. The larger shares of the sex workers are illiterate and they do not have enough knowledge about HIV/AIDS, but they can handle about half a million men per day with an average of 2 - 5 clients a day [14]. We feel proud that we live in an Islamic conservative society and moral values are better compared to the other western countries. But the real scenario is quite unbelievable. In Islam, sex outside marriage, premarital sex, extramarital sex and male to male sex are strongly prohibited, but these types sexual practices is increasing tremendously particularly 
among youths. It is mentionable that, all of the recreational areas in Bangladesh especially in Dhaka city are considered as the venue of sex place just after evening. All of the situation will put Bangladesh in more vulnerable position. With the increasing of HIV prevalence, the different studies about knowledge and awareness have been performed in various sites [18]-[22]. Hasan et al., [18] documented that almost everyone (98.30\%) heard the about HIV/AIDS and majorities (90.60\%) knew that the disease is transmissible from person to person and mainly by sexual contact but only $28.20 \%$ had some idea about the sign and symptoms of HIV. Sarkar et al., [23] identified the vulnerable groups which have lower level of preventive knowledge and transmission routes and ways of avoiding HIV/AIDS. Goni and Rahman [24] were conducted a study among the blood donors in Rajshahi City of Bangladesh and identified that $89.00 \%$ blood donors reported that HIV is transmitted through blood transfusion and only $1.00 \%$ of them had undertaken blood test before donation. Mondal et al., [25] used Bangladesh Demographic and Health Survey (BDHS), 2007 data to assess the level of awareness about HIV/ AIDS among ever married women and concluded that the respondents' education, husbands' education, husbands' occupation, age at marriage, watching television, electricity in the household, marital status and residence had statistically significant effects on HIV/AIDS awareness. However, studies on AIDS in the rural setting of Bangladesh are very scanty. Since HIV in not curable, it is very important to take the preventive measures. Therefore, the specific objective of this study is to find out the knowledge level about HIV/AIDS among the rural populations in Bangladesh.

\section{Data and Methodology}

In this study, data were collected from a total number of 100 villagers of Salmanpur from Comilla district, Bangladesh during 15-17 February, 2010. Respondents were interviewed using a standard questionnaire through purposive sampling technique. Both univariate and bivariate analyses have been performed to analyze the collected data. Firstly, univariate analysis was used to explore the background characteristics of the respondents, and later attempts were made to measure the knowledge level of the villagers regarding HIV/AIDS. In order to measure the knowledge level of HIV/AIDS, villagers were asked 13 different questions to respond either "yes" or "no". Each correct response (yes) was coded as 1, while incorrect response (no) was coded as 0 . Then total score were found by summing all the individual scores and finally mean value of this scores were used in this analysis as the level of knowledge about HIV/AIDS, where mean values were obtained by dividing total score by 13 for each respondent. To justify the total score for knowledge about HIV/AIDS, Cronbach's alpha $(\alpha)$ was calculated, which was 0.789 , suggested that inter-correlations among knowledge items were strong enough to use them as a single combined variable. The mean values of knowledge on AIDS range from $0.00-1.00$. The mean values were divided into three quartile, denoting the mean values 0.00 - 0.33 as very few knowledge, 0.34 0.66 as medium knowledge and 0.67 - 1.00 as enough knowledge.

\section{Results}

\subsection{Background Characteristics of Respondents}

The background information of the respondents is presented in Table 1. Table 1 shows that, most of the respondents were aged 20 - 40 years and only $13.00 \%$ were aged below 20 years. Among the respondents, $84.00 \%$ were married and $16.00 \%$ were unmarried, $46.00 \%$ were males and $54.00 \%$ were females. Almost one fourth of these villagers had no schooling experiences. However, $34.00 \%$ respondents were primary educated, $23.00 \%$ were secondary educated, $19.00 \%$ were higher educated. The study results also showed that these respondents were involved with different kinds of income generating activities; of them $11.00 \%$ were serviceman, $12.00 \%$ were involved with agricultural activities, $14.00 \%$ were doing business and the rest $63.00 \%$ were involved with various types of works. The monthly family income of the respondents were $<7000 \mathrm{Tk}$. (64.00\%), $7000-15,000$ Tk. (28.00\%) and <15,000 Tk. (8.00\%) respectively.

\subsection{Distribution of Knowledge about HIV/AIDS}

The percentage distribution of knowledge level about HIV/AIDS among the villagers is presented in Table 2. The study results revealed that, almost all the respondents (92.00\%) were ever heard about HIV/AIDS and 52.00\% were known the name of the HIV virus that transmits from one to other persons. But, around half of the respondents (51.00\%) were known that it is a communicable disease. Most of the respondents (77.00\%) were known 
Table 1. Background characteristics of the respondents.

\begin{tabular}{|c|c|c|}
\hline Variables & Frequency (n) & Percentage (\%) \\
\hline \multicolumn{3}{|l|}{ Age groups (in years) } \\
\hline$<20$ & 13 & 13.0 \\
\hline $20-40$ & 69 & 69.0 \\
\hline $40+$ & 18 & 18.0 \\
\hline \multicolumn{3}{|l|}{ Marital status } \\
\hline Married & 84 & 84.0 \\
\hline Unmarried & 16 & 16.0 \\
\hline Total & 100 & 100.0 \\
\hline \multicolumn{3}{|l|}{ Sex } \\
\hline Male & 46 & 46.0 \\
\hline Female & 54 & 54.0 \\
\hline \multicolumn{3}{|l|}{ Educational status } \\
\hline Illiterate & 24 & 24.0 \\
\hline Primary & 34 & 34.0 \\
\hline Secondary & 23 & 23.0 \\
\hline Higher & 19 & 19.0 \\
\hline \multicolumn{3}{|l|}{ Occupation } \\
\hline Service & 11 & 11.0 \\
\hline Farmer & 12 & 12.0 \\
\hline Business & 14 & 14.0 \\
\hline Others & 63 & 63.0 \\
\hline \multicolumn{3}{|c|}{ Monthly family income (in Taka) } \\
\hline$<7000$ & 64 & 64.0 \\
\hline $7000-15,000$ & 28 & 28.0 \\
\hline $15,000+$ & 8 & 8.0 \\
\hline Total & 100 & 100.0 \\
\hline
\end{tabular}

Table 2. Distribution of knowledge about HIV/AIDS among respondents.

\begin{tabular}{ccc}
\hline Variables & Yes (\%) & No (\%) \\
\hline Knowledge on HIV/AIDS & & \\
Have you ever heard about HIV/AIDS & 92.0 & 08.0 \\
Which virus spread AIDS & 52.0 & 48.0 \\
It is confirmed to death for AIDS & 77.0 & 23.0 \\
It is a communicable disease & 51.0 & 49.0 \\
Causes due to sexual relation with many men and women & 62.0 & 38.0 \\
Causes due to sexual relation with HIV positive person & 62.0 & 38.0 \\
Transmitted through affected mother to child & 52.0 & 48.0 \\
Causes due to taking infected blood & 53.0 & 47.0 \\
Causes due to use of others infected syringes & 63.0 & 37.0 \\
AIDS has no medicine & 72.0 & 28.0 \\
AIDS can prevent through increasing awareness & 62.0 & 38.0 \\
AIDS can prevent through maintaining religious rules & 54.0 & 46.0 \\
AIDS can prevent through using Condoms & 53.0 & 47.0 \\
Cronbach’s alpha, $\alpha=0.789$ & & \\
\hline
\end{tabular}


that, AIDS ensures death eventually and most of them (62.00\%) were mentioned that, AIDS causes due to heterosexual relations and also due to sexual relation with HIV infected persons. Around of the respondents (52.00\%) reported that, HIV can be transmitted through infected mothers to their children. But, a majority of them (63.00\%) was informed that, AIDS caused due to use of others infected syringes. About fourth-fifth of the respondents $(72.00 \%)$ were informed that, there is no medicine that cures AIDS. In case of prevention of AIDS, $62.00 \%$ respondents thought that, it can be prevented through increasing awareness among people. Around half of the respondents (54.00\%) thought that, through the maintaining religious rules HIV/AIDS can be prevented. Similar result was observed for the case of condoms use.

\subsection{Differentials of Knowledge Level on AIDS}

To justify the total score for level of knowledge about HIV/AIDS, Cronbach's alpha $(\alpha)$ was calculated and the values are presented in Table 3. Around half of the respondents (45.00\%) have medium knowledge $(\alpha=0.34$ $0.66)$ and $36.00 \%$ have enough knowledge ( $\alpha=0.67-1.00$ ) on AIDS, whereas $19.00 \%$ of the respondents have very few knowledge about AIDS.

The distribution of mean values of knowledge level about HIV/AIDS by some social, economic and demographic factors are presented in Table 4. The study results highlighted that the villagers have $55.00 \%$ knowledge on an average on AIDS. Also, the young and middle aged villagers have about $57.00 \%$ knowledge and the aged respondents (>40 years) have about $45.00 \%$ knowledge about HIV/AIDS. In case of marital status, the study result showed an increased level (56.00\%) of knowledge for married respondents than that of unmarried counterpart (53.00\%). Male villagers have more knowledge (57.00\%) than that of female villagers (55.00\%). Illiterate respondents showed a minimum level of knowledge $(48.00 \%)$, where as primary, secondary and higher educated respondents have shown $59.00 \%, 61.00 \%$ and $63.00 \%$ knowledge respectively. This showed that more educated respondents have more knowledge. Among all the occupational categories, farmers have shown lowest (47.00\%) knowledge level on HIV/AIDS; serviceman and businessman have shown approximately same levels of knowledge about HIV/AIDS (64.00\% and 63.00\% respectively). The study highlighted that less monthly income ( $<7000$ Tk.) were lower knowledge level (52.00\%) and higher monthly income (>7000 Tk.) were higher knowledge level (56.00\%).

\section{Discussion}

The HIV/AIDS epidemic has become one of the burning health issues across the world. HIV/AIDS awareness in Bangladesh has long been a topic of interest in research including all sectors of population because it has a direct relation with the prevalence of HIV/AIDS. The prevalence of HIV/AIDS is believed to be low in Bangladesh until now though the infection rate is increasing day by day and experts have classified the AIDS situation as concentrated epidemic. In the recent time, due to the urbanization and modernization our traditional family system breakup and our youth generation follow the western culture than the previous times. Along with the geographical location where Bangladesh is surrounded by the two higher HIV prevalence country (India and Myanmar), this put the Bangladesh is more vulnerable situation. Although poor medical facilities, lack of sufficient screening practice, unsafe sexual practice among the risk groups of population segment and the low level of knowledge and awareness about HIV/AIDS increasing the chance of more HIV infection. Compared to the other countries, Bangladeshi populations are more known about HIV/AIDS but possible causes of AIDS are fully undefined to them [18] [26]-[30]). The present study suggested that, about $92.00 \%$ of the respondents were heard about HIV/AIDS which was $90.00 \%$ among Nepalese and $85.00 \%$ among Cambodian and only $41.00 \%$ in India [30]. These findings strongly suggested that, it is needed to increase the current level of specific knowledge

\begin{tabular}{ccc}
\multicolumn{3}{c}{ Table 3. Level of knowledge on HIV/AIDS among respondents. } \\
\hline Category & Ranges of mean values of $\alpha$ & Percentage (\%) \\
\hline Very few knowledge & $0-0.33$ & 19.0 \\
Medium knowledge & $0.34-0.66$ & 45.0 \\
Enough knowledge & $0.67-1.00$ & 36.0 \\
Total (mean level) & 0.55 & 100.0 \\
\hline
\end{tabular}


Table 4. Distribution of mean values of knowledge level about HIV/ AIDS by some demographic and socio-economic factors.

\begin{tabular}{|c|c|c|}
\hline Variable & $\begin{array}{l}\text { Mean values of } \\
\text { knowledge }\end{array}$ & Percentage (\%) \\
\hline \multicolumn{3}{|l|}{ Age group (in years) } \\
\hline$<20$ & 0.57 & 13.0 \\
\hline $20-40$ & 0.57 & 69.0 \\
\hline $40+$ & 0.45 & 18.0 \\
\hline \multicolumn{3}{|l|}{ Marital status } \\
\hline Married & 0.56 & 84.0 \\
\hline Unmarried & 0.53 & 16.0 \\
\hline \multicolumn{3}{|l|}{ Sex } \\
\hline Male & 0.57 & 46.0 \\
\hline Female & 0.55 & 54.0 \\
\hline \multicolumn{3}{|l|}{ Educational status } \\
\hline Illiterate & 0.48 & 24.0 \\
\hline Primary & 0.59 & 34.0 \\
\hline Secondary & 0.61 & 23.0 \\
\hline Higher & 0.63 & 19.0 \\
\hline \multicolumn{3}{|l|}{ Occupation } \\
\hline Service & 0.64 & 11.0 \\
\hline Farmer & 0.47 & 12.0 \\
\hline Business & 0.63 & 14.0 \\
\hline Others & 0.54 & 63.0 \\
\hline \multicolumn{3}{|c|}{ Monthly family income (in Taka) } \\
\hline$<7000$ & 0.52 & 64.0 \\
\hline $7000-15,000$ & 0.56 & 28.0 \\
\hline $15,000+$ & 0.56 & 8.0 \\
\hline Total & 0.55 & 100.0 \\
\hline
\end{tabular}

about HIV/AIDS. It is possible by adding the HIV/AIDS related lessons in the secondary level and telecast broadly via the mass media. The results also showed that, married and young adolescents have the better knowledge than their unmarried and older counterparts. This might be due to the fact that the younger and married adolescents are more sexually active than that of other family members. So, it is necessary to aware about HIV/AIDS about all segments of the populations by giving the equal important. Level of education is an important factor which was also significantly associated with the level of knowledge and awareness of the HIV/AIDS. The present study is consistent with the previous study findings [23] [31]. In fact, education is the way of communication for any message. So, the community based health related educational programs should be strengthened through mass media, for which the general population will be gathered correct information about various epidemics especially HIV/AIDS.

\section{Conclusion}

Knowledge and awareness of HIV/AIDS infection among rural populations has a great importance in case of reducing and controlling this epidemic. Realizing these issues, especially in Bangladesh, the present study was conducted. We have collected information from 100 villagers among of them $46.00 \%$ are males and $54.00 \%$ are females. Among them, a few respondents were higher educated. Majority of the respondents ever heard about HIV/AIDS but half of them were reported that it was a communicable disease. More than half of the villagers 
believe that AIDS causes due to the sexual relations with many men and women but a good number of the respondents are unaware about the other causes of HIV/AIDS. Most of the respondents have the medium knowledge about HIV/AIDS and only one-third of the respondents have the enough knowledge. Around half portion of male, and young and middle aged villagers do not have enough knowledge about HIV/AIDS. Educated respondents were found more aware about the transmission of HIV. So education should be enhanced to the general people particularly for females. In the formal educational system especially in primary and secondary levels of education, topic about basic health should be included. Information should be provided to create knowledge and awareness about HIV/AIDS through health workers, doctors, teachers, and mass media among the general population. Special arrangement should be made to spread the knowledge on correct use of condoms including condom demonstration among people and especially among the couples. More comprehensive research is needed to the better understanding of the factors relevant to the development of risk reduction interventions.

\section{Acknowledgements}

The authors are very grateful to the respondents who were provided their valuable time and opinion about HIV/ AIDS to perform the study. The authors gratefully acknowledge the extreme co-operation received from the authority of Bangladesh Academy of Rural Development (BARD), Comilla to make a chance to conduct this study.

\section{Competing Interest}

The authors declare that they have no competing interests.

\section{Contribution of Authors}

All authors have contributed to the conceptualization, conduct, and analysis of this research, and all authors have participated in the manuscript drafting, editing, and revising. All authors have approved the final version of this manuscript.

\section{References}

[1] UNAIDS (2011) Core Slides: Global Summary of the AIDS Epidemic. Joint United Nations Program on HIV/AIDS (UNAIDS), Geneva.

[2] CDC (2001) Morbidity and Mortality Weekly Report. Center for Disease Control and Prevention (CDC).

[3] UNAIDS (2010) UNAIDS Report on the Global AIDS Epidemic. Joint United Nations Program on HIV/AIDS (UNAIDS), Geneva.

[4] Huq, N.L. and Chowdhury, M.E. (2012) Assessment of Utilization of HIV Interventions by Sex Workers in Selected Brothels in Bangladesh. An Exploratory Study. The Qualitative Report, 17, 1-18.

[5] Ramjee, G. and Gouws, A.E.E. (2002) Prevalence of HIV among Trucks Drivers Visiting Sex Workers in KwaZula Natal, South Africa. Sexually Transmitted Diseases, 29, 44-49. http://dx.doi.org/10.1097/00007435-200201000-00008

[6] Islam, M.M. and Conigrave, K.M. (2008) HIV and Sexual Risk Behaviors among Recognized High-Risk Groups in Bangladesh: Need for a Comprehensive Prevention Program. International Journal of Infectious Diseases, 12, 363-370. http://dx.doi.org/10.1016/j.ijid.2007.12.002

[7] Mondal, M.N.I. and Shitan, M. (2014) Relative Importance of Factors on Life Expectancy in the Low and Lower Middle Income Countries. Journal of Epidemiology, 24, 117-124. http://dx.doi.org/10.2188/jea.JE20130059

[8] UNAIDS (2013) Global Report, UNAIDS-Report on the Global AIDS Epidemic 2013. Joint United Nations Program on HIV/AIDS (UNAIDS), Geneva.

[9] Mondal, M.N.I. and Shitan, M. (2013) Factors Affecting the HIV/AIDS Epidemic: An Ecological Analysis of Global Data. African Health Sciences, 13, 294-303.

[10] WHO (2013) World Health Statistics 2013. World Health Organization (WHO), Geneva.

[11] UNAIDS (2014) Global AIDS Response Progress Reporting 2014. Joint United Nations Programme on HIV/AIDS (UNAIDS), Geneva.

[12] WHO (2011) HIV/AIDS in the South-East Asia Region: Progress Report 2011. World Health Organization, Geneva.

[13] WHO (2011) Regional Health Sector Strategy on HIV, 2011-2015. World Health Organization, Regional Office for South-East Asia, New Delhi. 
[14] MOHWF (2012) National HIV Serological Surveillance, 2011; Bangladesh. National AIDS/STD Program. Ministry of Health and Family Welfare (MOHWF), Directorate General of Health Services, Ministry of Health and Family Welfare, Bangladesh.

[15] Mondal, M.N.I., Hiroshi, T., Yasush, O., Tamie, S. and Nobuhiko, O. (2009) HIV Acquisition and Transmission in Bangladesh: Turning to the Concentrated Epidemic. Japanese Journal of Infectious Diseases, 62, 111-119.

[16] MOHWF (2010) National AIDS/STD Program (NASP). Ministry of Health and Family Welfare (MOHWF), Directorate General of Health Services, Bangladesh.

[17] Mondal, M.N.I. and Shitan, M. (2014) Birth Process Modeling of HIV Infections for Three Main Cities of Bangladesh. Pakistan Journal of Statistics, 30, 487-498.

[18] Hasan, A.T.M.H., Hasan, R., Khan, Z.R., Nuzhat, E. and Arefin, U. (2013) Influence of Socio-Demographic Factors on Awareness of HIV/AIDS among Bangladeshi Garment Workers. SpringerPlus, 2, 174. http://dx.doi.org/10.1186/2193-1801-2-174

[19] Mondal, M.N.I., Islam, M.R., Rahman, M.O., Rahman, M.S. and Hoque, N. (2012) Determinants of HIV/AIDS Awareness among Garments Workers in Dhaka City, Bangladesh. World Journal of AIDS, 2, 312-318. http://dx.doi.org/10.4236/wja.2012.24042

[20] Mondal, M.N.I., Khan, M.A.R., Islam, M.R. and Mamun, A.A. (2005) Commercial Sex Workers in Brothels Are Hallmark of HIV Epidemic in Bangladesh. Pakistan Journal of Life and Social Sciences, 3, 1152-1158.

[21] Mondal, M.N.I., Hossain, M.M. and Rahman, M.M. (2008) Knowledge and Awareness about HIVAIDS among Garments Workers in Gazipur District, Bangladesh. The Social Sciences, 3, 528-530.

[22] Islam, M.M., Conigrave, K.M., Miah, M.S. and Kalam, K.A. (2010) HIV Awareness of Outgoing Female Migrant Workers of Bangladesh: A Pilot Study. Journal of Immigrant and Minority Health, 12, 940-946. http://dx.doi.org/10.1007/s10903-010-9329-5

[23] Sarkar, P., Mostofa, G. and Rahman, M. (2013) Knowledge of Fearfulness of HIV/AIDS between Floating and Frequently Moving Population of Three Metropolitan Cities in Bangladesh. Journal of Infectious Diseases and Immunity, 5, 1-9. http://dx.doi.org/10.5897/JIDI09.017

[24] Goni, A. and Rahman, M. (2012) Knowledge and Awareness on HIV/AIDS among Blood Donors: A Study at Rajshahi, Bangladesh. Journal of Public Health and Epidemiology, 4, 70-77.

[25] Mondal, M.N.I., Rahman, M.M., Rahman, O.R. and Akther, M.N. (2012) Level of Awareness about HIV/AIDS among Ever Married Women in Bangladesh. Food and Public Health, 2, 73-78. http://dx.doi.org/10.5923/j.fph.20120203.03

[26] Lal, P., Nath, A., Badhan, S. and Gopal, K. (2008) A Study of Awareness about HIV/AIDS among Senior Secondary School Children of Delhi. Indian Journal of Community Medicine, 33, 190-192. http://dx.doi.org/10.4103/0970-0218.42063

[27] Azim, T., Khan, S.I., Haseen, F., Huq, N.L., Hanning, L., Pervez M.M., Chowdhury, M.E. and Sarafian, L. (2008) HIV and AIDS in Bangladesh. Journal of Health, Population, and Nutrition, 26, 311-324.

[28] Chaudhury, M.A., Naeem, M., Iqbal, R. and Shabbir, I. (2005) Level of Awareness about HIV/AIDS among Trucks Drivers and Their Attitude towards Persons with AIDS. Global Journal of Medical Science, 3, 18-23.

[29] Khan, M.A., (2002) Knowledge on AIDS among Female Adolescents in Bangladesh, Evidence from the Bangladesh Demographic and Health Survey Data. Journal of Health, Population, and Nutrition, 20, 130-137.

[30] Rahman, M.M., Kabir, M. and Shahidullah, M. (2009) Adolescent Knowledge and Awareness about AIDS/HIV and Factors Affecting Them in Bangladesh. Journal of Ayub Medical College Abbottabad, 21, 3-6.

[31] Sarma, H. and Oliveras, E. (2013) Implementing HIV/AIDS Education: Impact of Teachers Training on HIV/AIDS Education in Bangladesh. Journal of Health, Population, and Nutrition, 31, $20-27$. http://dx.doi.org/10.3329/jhpn.v31i1.14745 
Scientific Research Publishing (SCIRP) is one of the largest Open Access journal publishers. It is currently publishing more than 200 open access, online, peer-reviewed journals covering a wide range of academic disciplines. SCIRP serves the worldwide academic communities and contributes to the progress and application of science with its publication.

Other selected journals from SCIRP are listed as below. Submit your manuscript to us via either submit@scirp.org or Online Submission Portal.
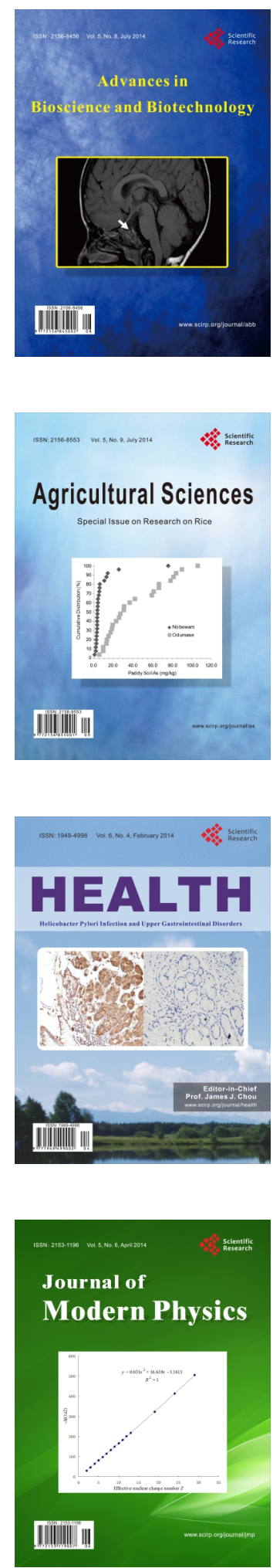
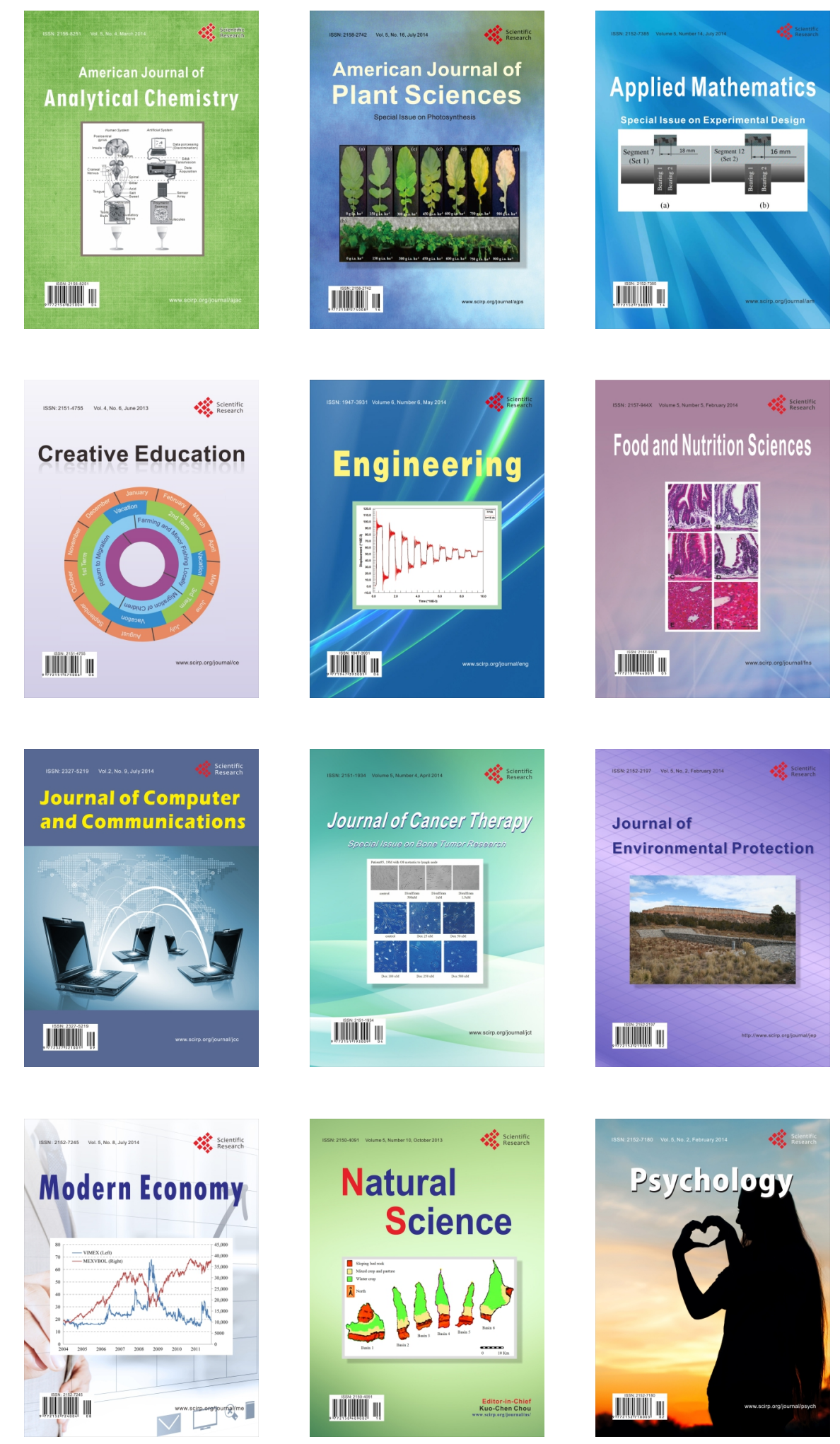